\title{
|||||||||||||||||||||||||||||||||||||||||||||||||||||||||||||||||||.
}

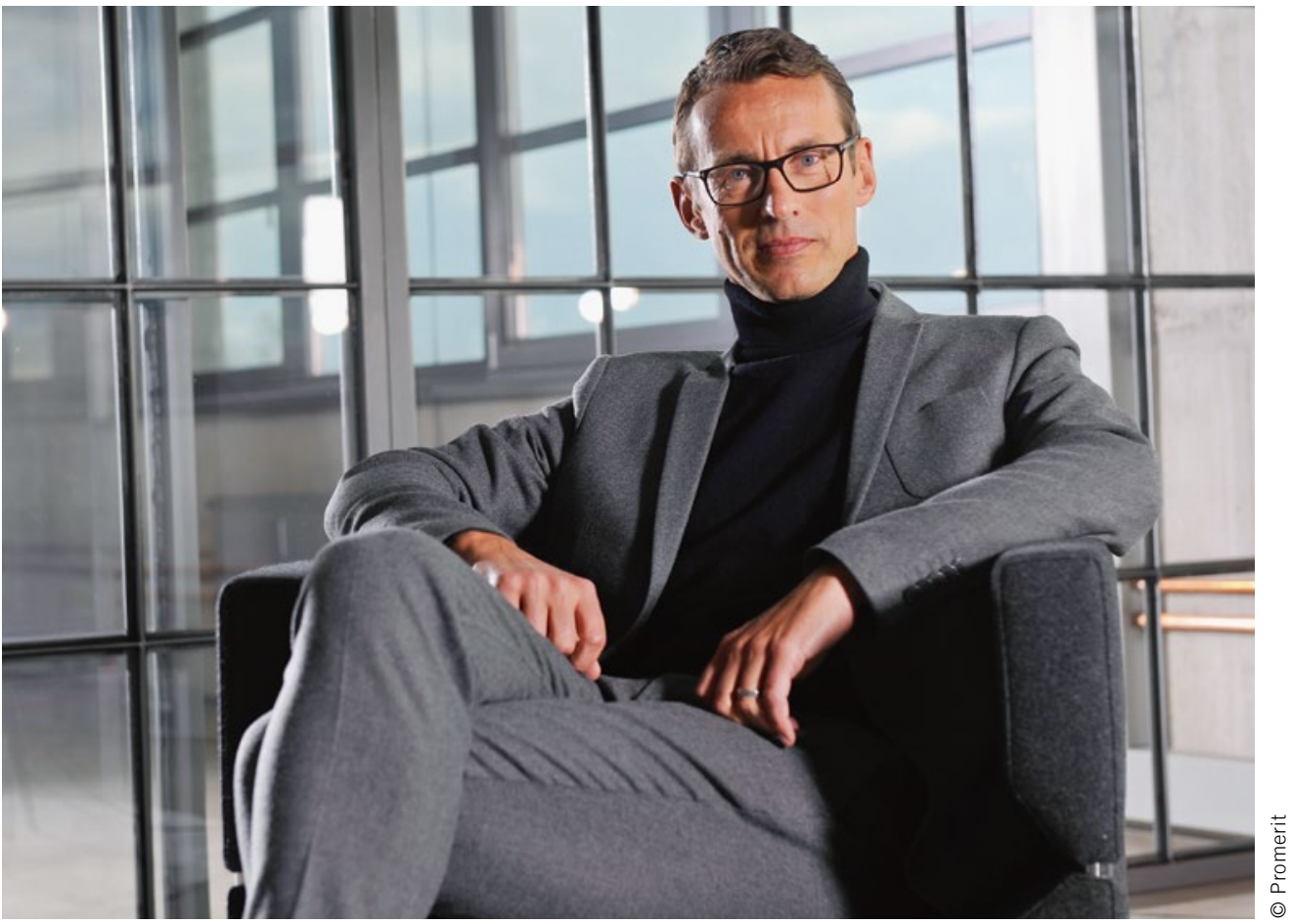

Dipl.-Wirt.-Ing. Kai Anderson Gründungspartner und Vorstand der Promerit AG

\section{Digital und agil für die Transformation}

Die Digitalisierung verändert das Leben der Menschen drastisch und stellt Unternehmen vor enorme Herausforderungen. Diese Gewissheit hatte sich vor ein paar Jahren noch nicht allgemein durchgesetzt - zumindest nicht in Branchen, die bislang mit Informationstechnik, Cloud und Internet nicht so viel zu tun hatten. In der Fahrzeugindustrie beschäftigte man sich zwar schon früh mit autonom fahrenden Systemen und Infotainment-Modulen, die primär die Passagiere und bald auch den Fahrer mit Unterhaltung oder neuen Arbeitsmöglichkeiten vom Fahrgeschehen ablenken sollten. Aber nur wenige dachten daran, das Gesamtsystem des individuellen Verkehrs infrage zu stellen. Heute arbeiten die Chefstrategen der Automobilhersteller an Plänen, ob Software-Apps wie die von Uber den Personentransport revolutionieren und ihn zu einem Commodity-Service werden lassen. Dies ist eine Dienstleistung, die jederzeit und überall genutzt werden kann, ohne einen Pkw zu besitzen. Kein Fahrer, kein Parken, keine Staus. Ist das Zukunftsmusik? Nein, dieses Szenario dürfte in vielen Megastädten zwischen 2030 und 2035 wahrwerden.

Das Geschäftsmodell der OEMs steht also in Frage - und hier ist die deutsche Automobilindustrie noch nicht gut aufgestellt. Wir sollten vermeiden, dass die zukünftigen Mobilitätsplattformen aus den USA oder Asien kommen. Was sich mit der Digitalisierung ebenfalls verändert, ist unser Bild von Arbeit und Arbeitsplatz. Die Trennschärfe von Büro und Zuhause ver- schwimmt durch ein Home Office immer mehr. Neue Arbeitsmethoden bestimmen zunehmend unseren beruflichen Alltag. Mit Kanban und Scrum ist die Automotivebranche gar nicht schlecht unterwegs. Design Thinking findet nach und nach seinen Weg aus den IT-Abteilungen in die Pkw-Produktentwicklung, auch wenn der Produktentstehungsprozess noch wenig Spielraum für hybride Strukturen lässt. Mit Blick auf das Prinzip der Netzwerkökonomie ist die Automobilindustrie mit ihren filigranen Zuliefererstrukturen sogar recht weit, wenn auch die Fehleranfälligkeit des Gesamtsystems noch zu hoch ist.

Was uns allerdings wirklich abgeht, ist eine andere Kultur als die, wie wir sie heute noch allzu gern mit „Benzin im Blut“ beschreiben. Der Ausdruck ist Synonym für ein Beharrungsmoment im letzten Jahrhundert, das wir schleunigst überwinden müssen. Wir sind nicht mehr die wichtigste, angesehenste, attraktivste Branche der Welt. Keine leichte Erkenntnis, aber die deutsche Autoindustrie muss sich im Zeitalter der Digitalisierung neu erfinden. Das kann nur funktionieren, wenn wir das auf den Prüfstand stellen, was uns in der Vergangenheit erfolgreich gemacht hat. Wenn wir das Wesen der Digitalisierung nicht nur als Technikthema verstehen, sondern auch als Idee, unsere Produkte, Services, Prozesse und Regeln vom Nutzen unserer Kunden konsequent neu zu denken, sind wir auf dem richtigen Weg. Ladies and Gentlemen, start your digital engines! 